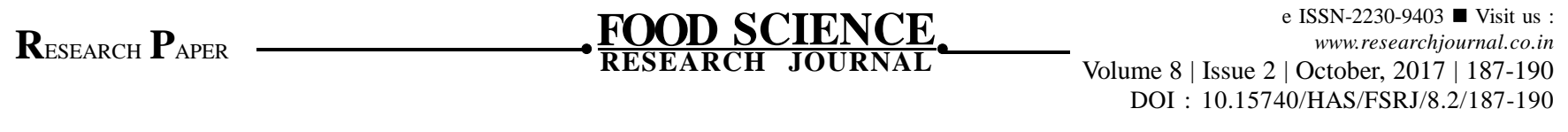

\title{
An iron rich food supplement: Niger seed Laddoo
}

\author{
Deepika Baranwal and Rashmi Singh
}

In India where Iron Deficiency anemia is a most common health problem, there is a need to know about the iron rich food supplements. These supplements should be including in our daily diet. Niger seed (Guizotia abyssinica) is a type of oilseed crop which is reported to be containing very high amount of iron in plant based foods and may be of immense help in improving the iron status of vulnerable population group. In the present study, an iron rich food supplement i.e. niger seed Laddoo has been prepared and its nutrient analysis was done by standard procedure. This study showed that the supplement made with two parts of niger seeds and one part of jaggery i.e. 2:1 ratio was found to be more acceptable. The highly accepted variation was analyzed for its biochemical composition. It contained $20.71 \mathrm{~g}$ protein, $34 \mathrm{~g}$ of fat, $7.83 \mathrm{~g}$ crude fibre, $213 \mathrm{mg}$ calcium, $42.61 \mathrm{mg}$ iron, $4.7 \mathrm{~g}$ ash per $100 \mathrm{~g}$ of Laddoo. It was concluded in the present study that niger seed Laddoos had a large amount of nutrients among other plant foods. Due to its easy availability and convenient method to prepare the Laddoo, it can be used for preventing anaemia and malnutrition.

Key Words : Niger seeds, Iron, Supplement, Food.

How to cite this article : Baranwal, Deepika and Singh, Rashmi (2017). An iron rich food supplement: Niger seed Laddoo. Food Sci. Res. J., 8(2): 187-190, DOI : 10.15740/HAS/FSRJ/8.2/187-190. 